\title{
O ADOECIMENTO PELO CANCER DE LARINGE*
}

\author{
THE ILLNESS NARRATIVE FOR LARYNX CANCER
}

\author{
Márcia Maria Fontão Zago** \\ Elizabeth Barichello*** \\ Sabrina Hannickel ${ }^{* * * *}$ \\ Namie Okino Sawada**
}

ZAGO, MMF et al. O adoecimento pelo câncer de laringe. Rev Esc Enf USP, v. 35, n. 2, p.108-14 ,jun, 2001.

\begin{abstract}
RESUMO
Com a finalidade de aprimorar a assistência ao laringectomizado, este estudo teve o objetivo de compreender o adoecimento pelo câncer de laringe na visão do paciente e sua família. Participaram do estudo 14 pacientes laringectomizados e familiares, em diferentes periodos pós-operatórios. Na análise das narrativas identificamos categorias que foram interpretadas sob a visão antropológica da cultura. Na interpretação dos participantes, o processo é permeado pelo sofrimento, pela busca de estratégias de enfrentamento, pela valorização de sobreviver à cirurgia, ou seja, pressupostos culturais que diferem do modelo biomédico dos profissionais e que devem ser considerados na sua reabilitação.
\end{abstract}

PALAVRAS-CHAVE: Laringectomia. Câncer da laringe. Assistência pós-operatória.

\section{ABSTRACT}

With the purpose of improving the care of laryngectomized patients, the aim is to understand the illness experience of patients and families of having larynx cancer. The participants were 14 laryngectomized patients and their families, in different post-surgical periods. The narrative analysis searched for categories which were understood on the basis of an anthropological focusing the culture. The understanding that the participants had of the illness experience of having a larynx cancer shows us that this process is one of suffering, of searching of strategies of coping, of evaluating the survival to the surgical treatment, which were based on the cultural system, which is different from the biomedical model of the health professionals and they must be considered in the approach for the rehabilitation.

KEYWORDS: Laryngectomy. Laryngeal neoplasm. Postoperative care.

\section{INTRODUÇÃO}

A relação entre cultura, crenças e comportamentos relacionados com a saúde-doença é complexa. As experiências pessoais, as atitudes da família e as crenças grupais interagem entre si e fornecem uma estrutura de referência para as tomadas de decisões durante o processo de doença. Estes aspectos também podem afetar a comunicação entre o ser doente e os profissionais de saúde que o assistem.

As atitudes sociais frente ao câncer, a participação do paciente no tratamento e as suas estratégias de enfrentamento, são conhecidas por serem profundamente influenciadas pelas normas e crenças culturais. No contexto da enfermagem, a sensibilidade cultural é definida como a consciência das influências culturais na saúde, o respeito às crenças e comportamentos específicos e modificação do fornecimento do cuidado à saúde, considerandose os fatores culturais (NAVON, 1999).

Trabalho desenvolvido com subvenção do CNPq, processo no. 520604/96-2

** Enfermeira. Professora Doutora da Escola de Enfermagem de Ribeirão Preto - USP. Coordenadora do GARPOL aringectomizados. mmfzago@glete.eerp.usp.br

*** Enfermeira. Pesquisadora do GARPO-Laringectomizados. Escola de Enfermagem de Ribeirão Preto - USP.

**** Aluna de Graduação em Enfermagem. Escola de Enfermagem do Ribeirão Preto - USP. Participante do GARPO-Laringeclomizados. Bolsista do CNPq. 
No nosso convivio com a pessoa com câncer de laringe, no Grupo de Apoio e Reabilitação da Pessoa Ostomizada (GARPO - Laringectomizados), observamos que muitas vezes referimo-nos a um determinado aspecto da doença ou tratamento, que causa estranheza ou reações diferenciadas entre os pacientes e familiares. Essa observação levou-nos a considerar o quanto o nosso conhecimento profissional pode ser distinto do conhecimento e crenças dos pacientes e familiares, a cerca do câncer de laringe e das condutas terapêuticas. Dessa consideração, elaboramos este estudo que tem o objetivo de "compreender o adoecimento pelo câncer de laringe na visão do paciente e família", buscando assim, favorecer a assistência ao laringectomizado e sua familia e adequar nossos conhecimentos aos deles.

\section{A EXPERIÊNCIA DA ENFERMIDADE: CONSIDERAÇÕES SOCIO-CULTURAIS}

Segundo ALVES (1993), antropólogos e sociólogos têm buscado estudar as crenças e valores médicos dos indivíduos que constituem respostas socialmente organizadas para a doença. $\mathrm{O}$ autor emprega a expressão "experiência da enfermidade", como uma categoria analitica que se refere aos meios pelos quais os indivíduos e grupos sociais respondem a um dado episódio de doença. Esclarece ainda que essa categoria parte do pressuposto de que as pessoas reproduzem conhecimentos médicos existentes no contexto sociocultural em que se inserem. Entretanto, a interpretação de como os indivíduos se apropriam de um conjunto de idéias e crenças relativas à doença, tem sido objeto de estudo da antropologia.

KLEINMAN (1988) é um dos pesquisadores da área da antropologia médica que tem enfatizado as estruturas cognitivas subjacentes aos relatos individuais sobre a doença, constituindo um referencial teóricometodológico, que busca compreender as dimensões cognitivas e sociais incorporadas nas representações individuais, por meio do conceito de Modelo Explicativo.

O conceito de Modelo Explicativo da enfermidade/ doença consiste nas noções sobre um episódio de doença e seu tratamento que são empregadas por todos aqueles engajados no processo clínico. Este conceito objetiva estabelecer um quadro analitico capaz de conduzir comparações entre culturas e sistemas de tratamento. Os Modelos Explicativos (ME) são considerados como estando ligados a conjuntos específicos de conhecimentos e valores fundamentados nos diferentes setores do sistema médico.

Para o autor, o conhecimento médico de um individuo tem uma história particular pois, é constituído de e por experiências diversas. Assim, a interpretação da enfermidade tem uma dimensão temporal, está continuamente sendo reformulada e reestruturada, devido aos processos interativos sociais (amigos, família, vizinhos e terapeutas). Metodologicamente, o estudo da interpretação da enfermidade deve levar em conta esses aspectos.

A construção do $\mathrm{ME}$ está fundamentada em aspectos diferenciados, de acordo com a perspectiva daqueles que estão envolvidos no processo. Basicamente, a diferenciação mais específica é aquela relacionada entre o paciente e os agentes de saúde, ou seja, o ME médico e o ME leigo. Essa diferenciação, segundo o autor, referese a diferenciação entre o conceito de enfermidade médica e doença (disease/illness). A enfermidade médica referese ao processo de alterações, em nível biológico e psicológico, que provocam o distúrbio corporal. Há uma preocupação entre os agentes de saúde pelo diagnóstico, através da análise dos sinais e sintomas apresentados pelo paciente e, posteriormente, à terapêutica e que se referem exclusivamente ao indivíduo portador do distúrbio. Por outro lado, este referencial está ligado à prática de saúde da medicina ocidental. O conceito leigo de doença está relacionado com a forma como ela é vivenciada, percebida e contém os significados sociais que permitem enquadrá-la em algo compreensivel e sob determinado controle. É um processo do qual participam não só o paciente mas, também, a sua família. Desse modo, o conceito de enfermidade refere-se aos pressupostos socioculturais dos agentes de saúde (modelo médico, enfermidade médica), enquanto que o conceito de doença refere-se aos pacientes/familiares (modelo leigo).

É fundamental que os agentes de saúde, entre eles os enfermeiros que assistem o paciente com câncer, compreendam essas diferentes realidades, visto que elas poderão direcionar o processo de comunicação do profissional de saúde com o paciente/família, a adesão ao tratamento proposto, a avaliação por parte do paciente da eficácia do tratamento proposto ou realizado e a forma de utilização dos serviços de saúde.

Na perspectiva deste estudo, o nosso interesse está em compreender o modelo leigo do paciente laringectomizado e sua família, em relação ao câncer de laringe e as intervenções terapêuticas realizadas.

\section{O PERCURSO METODOLÓGICO}

Frente ao objetivo e aos pressupostos teóricos, este estudo foi desenvolvido sob a abordagem metodológica da narrativa. Essa abordagem foi selecionada pois, segundo KLEINMAN (1988), a narrativa da doença é um processo que reconstroe a experiência da doença pelo paciente e família, integrando as dimensões cognitivas, afetivas e morais que os indivíduos trazem no curso da doença crônica. FLICK (1998) complementa que esta técnica fornece uma relação análoga entre a apresentação da 
narrativa e a experiência narrada. Assim, na retrospectiva da narrativa das experiências, os eventos da história de vida são relatados, em princípio, no modo em que eles foram vivenciados pelo narrador como ator.

Participaram do estudo 14 pacientes laringectomizados e seus familiares integrantes do GARPO - Laringectomizados, que concordaram em participar do estudo.

A coleta de dados foi realizada através de entrevistas semi-estruturadas, direcionadas por questões que focalizavam as reações ao diagnóstico e ao tratamento, o curso da doença, mudanças no estilo de vida pela doença e pelo tratamento, a causa do câncer e a realidade clínica atual.

As entrevistas tiveram duração média de 45 minutos a 2 horas e foram realizadas, .em média, 3 entrevistas com cada participante e sua família. Com os pacientes que utilizavam a voz esofágica, as entrevistas foram gravadas; com os que utilizavam a voz bucal ou mímica labial, transcreviamos as entrevistas imediatamente após, validando o conteúdo com o paciente. As entrevistas com os familiares foram todas gravadas. A primeira entrevista ocorreu após o encontro grupal do GARPO-Laringectomizados e as seguintes foram realizadas no domicílio do paciente. As entrevistas ocorreram em um período de 16 meses.

Concomitante a coleta de dados, teve início a análise das narrativas na busca das suas propriedades estruturais, em relação às funções sociais do adoecimento. Estas propriedades estruturais têm padrões recorrentes que podem ser identificados e usados para interpretar cada segmento da narrativa. As propriedades podem ser identificadas com a leitura atenta, identificando-se como a história do adoecimento está organizada, desenvolvida, onde começa e termina, tendo como foco o curso das considerações pessoais e comuns aos atores, segundo as diretrizes propostas por COFFEY; ATKINSON (1996). As propriedades são, então, interpretadas e constituem categorias analiticas.

Antes de iniciarmos a coleta de dados, o estudo foi submetido a um Comitê de Normas Éticas em Pesquisa e todos os participantes assinaram o consentimento informado e concordaram, por escrito, com o uso do gravador nas entrevistas.

\section{O ADOECIMENTO PELO CÂNCER}

Os pacientes participantes deste estudo são todos do sexo masculino, na faixa etária entre 52 - 71 anos, na sua maioria casados e aposentados. O tempo da realização da cirurgia variava de 8 meses a 6 anos, e apenas 4 deles utilizavam a voz esofágica para se comunicar. Entre os familiares, a maioria dos participantes eram filhas(os) e esposas.

Pelas narrativas, emergiram as diversas dimensões interpretativas, pelas quais, a realidade da doença e do tratamento e seus significados foram construídos, em relação ao mundo da experiência. Essas dimensões são construídas aos poucos, dos encontros com os agentes de saúde, com os participantes do seu contexto familiar e social e da própria experiência corporificada. Neste processo, foram identificadas as seguintes dimensões do adoecimento pelo câncer que serão apresentadas e discutidas a seguir. Para exemplificar, as dimensões serão apresentadas com fragmentos das narrativas em que os participantes serão identificados com nomes fictícios.

\subsection{O FUNCIONAMENTO DO CORPO}

Os pacientes/familiares associam os conhecimentos do seu sistema cultural de referência com as informações médicas obtidas junto aos agentes de saúde. Recriam, desse modo, o modelo de funcionamento do corpo como tubulação, como descrito por Boyle (apud HELMAN, 1994). Nesta re-criação, "a garganta" (laringe e traquéia) é o cano que junta a boca e o nariz ao pulmão (cavidade). Neste modelo, a condição de saúde é estabelecida pelo fluxo ininterrupto de substâncias (ar, sangue, urina e outras) entre as cavidades ou entre uma cavidade e o exterior do corpo, por um orificio. A doença é considerada como o resultado do bloqueio do tubo. Assim, o câncer é "que nem uma bola que entope a laringe".

Senhor José: "A garganta, a laringe é um cano que tem as cordas vocais e serve para jogar fora o catarro. $O$ catarro fica no pulmão e tem sempre quando a gente fuma".

\subsection{O SIGNIFICADO DOS SINTOMAS INICIAIS}

Para os participantes, os sintomas iniciais da doença: "catarro, tosse, ardume na garganta, dor de garganta", são analisados e interpretados, sob o seu sistema de referência, como sinais normais. Assim, "É normal ter problema de garganta, resfriado e gripe em várias fases da vida, todo mundo tem". Neste sistema de referência, esses sinais são normais pois há a manutenção das rotinas de vida. Conse-qüentemente, as medidas terapêuticas tomadas estão inclusas no sistema de saúde informal (conselhos médicos de familiares, amigos, parentes mais velhos e farmacêutico amigo), no uso de remédios caseiros (chás, gargarejos) e alopáticos (xarope, pastilhas, remédios para gripe).

As pessoas quando adoecem, em geral, recorrem a automedicação ou escolhem quem consultar no sistema informal de saúde. Segundo HELMAN (1994), as escolhas são influenciadas pelo contexto em que ocorrem os problemas de saúde, o que inclui os tipos de assistência disponiveis, as condições do paciente/ família em arcar com as despesas da assistência e o modelo explicativo que o paciente e a família utilizam 
para explicar o seu estado de saúde. O autor esclarece que quando a doença é considerada anormal, a escolha recai no sistema médico formal. Algumas vezes, o sistema médico pode ser utilizado para resolver os sintomas fisicos e o sistema de saúde popular para a causa ("mal da alma"). Assim, a escolha pelo tratamento médico formal também demonstra o poder social e simbólico deste tipo de assistência para o paciente e família.

Senhor Antonio: "O cigarro e a fumaça vai inflamando a garganta. Então, o catarro é normal para quem fuma, quando tem gripe, na mudança do tempo. Ai, a gente tosse para jogar fora o catarro, pela garganta. Mas, isso é normal! De vez em quando eu ia na farmácia e o meu amigo que trabalha lá, há muito tempo, me dava pastilha ou remédio para resfriado, ou eu tomava chá de alho, chá de erva-cidreira com mel, ciosa quente para soltar o catarro e melhorar a tosse. Isso é normal! A bebida, a bebida não faz mal, faz muito menos mal que o fumo. A bebida acalma!"

Senhor Marcelo: "Eu sabia que o que eu tinha era normal. Como eu já estou velho, aposentado, sem ter o que fazer, a minha esposa achou que era coisa da alma e eu procurei a benzedeira".

\subsection{A RE-SIGNIFICAÇÃO DOS SINAIS E SINTOMAS}

Com o passar do tempo, com a persistência dos sinais e sintomas iniciais e o aparecimento de novos sinais e sintomas, como o "catarro com sangue", "tosse forte", "falta de apetite", "ranhura na garganta", "emagrecimento rápido", e a não resolução das medidas terapêuticas do sistema de saúde informal, esses sinais e sintomas começam a ser questionados pela rede familiar quanto ao seu real significado. É com a mudança de comportamento verbal e não-verbal do paciente, percebida pelos familiares e/ou amigos, como "depressão, braveza, nervosismo e a falta ao trabalho", que a rede de apoio do paciente desenvolve o processo de resignificação. Esses problemas começam, então, a ser considerados como agravantes e potenciais para a possibilidade de uma "infecção, inflamação, coisa ruim, piora da condição". Dessa forma, começa a "apresentação da doença", segundo o sistema de referência de conhecimento cultural da família, com todas as fases do sofrimento, pelas expectativas de ser "algo ruim".

O adoecimento pela doença crônica envolve experiências subjetivas de mudanças fisicas e/ou emocionais e a confirmação dessas mudanças por parte de outras pessoas. Para que haja esta confirmação, deve haver consenso entre a rede de apoio sobre o que constitui uma condição sadia e um sinal ou sintoma anormal de saúde. Deve haver, também, uma conduta padronizada pela qual uma pessoa doente possa chamar a atenção sobre as mudanças, as condições anormais, para que receba cuidados e apoio.
Cada cultura possui uma linguagem própria de sofrimento que faz a ligação entre as experiências subjetivas de mal-estar e o seu reconhecimento social. Os fatores culturais determinam quais os sinais e sintomas que devem ser percebidos como anormais. Ao mesmo tempo, eles ajudam a dar forma às mudanças fisicas e emocionais difusas que as colocam em um padrão identificável, tanto para a vítima quanto para as pessoas que a cercam. O padrão resultante dos sinais e sintomas pode ser denominado de entidade doença ("a doença") e representa o primeiro estágio do adoecimento (KLEINMAN, 1988).

Nessa situação, a família é o ponto fundamental para as decisões a serem tomadas. É ela quem decide pela busca do tratamento médico no sistema formal (Zola apud HELMAN, 1994). Entretanto, essa busca nem sempre é fácil. Os participantes do estudo deixaram claro que ela é permeada pelo sofrimento devido a demora do agendamento da consulta médica, na demora pelos exames diagnósticos, na falta de uma comunicação médico-paciente-famillia efetiva, negligência na avaliação dos sinais e sintomas do paciente e condutas terapêuticas ineficazes.

Senhor Ricardo: "Ai, depois de muito tempo, a tosse ficou pior. Era uma coisa que incomodava na garganta, parecia que tinha uma bola entupindo. Ficava ruim depois que eu engolia a comida, ficava raspando".

Senhor Manuel: "Eu não tinha dor e engolia bem! Ficava ruim depois que eu engolia, ficava um ardume. Eu chupava pastilha que eu comprei na farmácia. Depois de uns 3 meses não melhorou e aí eu achei, a minha filha achou que era melhor procurar um médico. Eu achava que era uma inflamação, uma infecção".

Bernadete (filha de Sr. Manuel): "Na verdade, ele começou a ficar muito incomodado com isso. No começo não dei atenção. Minha mãe fazia chá, ele chupava pastilha. Mas ai, ele foi ficando sem comer, dizia que não tinha apetite. Depois de 3 a 4 meses eu percebi que ele tinha emagrecido muito. Isso já não é normal! Ele ficava acabrunhado, não conversava, não saia de casa. Tinha dia que ele estava muito nervoso! Foi ai que eu percebi que ele não estava bem. Contei para o meu irmão e minha mãe concordou que ele não estava bem. Então, só tinha uma solução: levá-lo ao médico!"

\subsection{O SIGNIFICADO DO DIAGNÓSTICO}

Após percorrem vários médicos do sistema de saúde formal, os pacientes foram todos encaminhados a um serviço de atendimento de referência terciária (hospital universitário). Este processo de encaminhamento, da primeira consulta até o atendimento que resultou em um diagnóstico definitivo, teve uma variação de 3 meses a 1 ano. Enquanto o encaminhamento não se definiu, as medidas terapêuticas 
para abrandar os sinais e sintomas foram paliativos, variando de remédios caseiros, busca pelo sistema informal de saúde (benzedeiras) e analgésicos receitados por amigos, familiares e farmacêuticos (nem sempre profissionais e, em geral, balconistas de farmácia), preocupados em ajudar o paciente e a família a abrandar os sintomas. De qualquer modo, essa etapa do adoecimento é sempre permeada pelo sofrimento do paciente e de toda a sua rede de apoio.

Desde a primeira consulta médica, o paciente está sempre acompanhado de familiares e começa a delinear-se o significado da doença. Este processo tem início com a indicação do exame de biópsia, "eu não sou bobo, era para saber se a doença é ruim... câncer!" Começa, então, a ser delineado a expectativa pelo significado da doença como algo inesperado, de péssimo prognóstico. A confirmação do diagnóstico ocorre com a comunicação do médico, que nem sempre é feita utilizando a palavra câncer, mas com rótulos que buscam amenizar a situação, como: é um machucado, é uma lesão, é doença grave, é um tumor. Independente da intenção do médico, fica claro que o paciente e a família detectam a realidade da situação, pelo seu próprio sistema de referência sociocultural.

Senhor Romualdo: "A minha respiração estava dificil. Procurei vários médicos, a garganta estava fechando, eu piorava. O médico do posto olhou e disse que eu não tinha nada, o outro passou remédio para asma! Aerossol! Imagina! Foi quando eu fui no Hospital das Clínicas que o especialista em garganta descobriu "a doença"! Sabe quanto tempo isso tudo demorou? Mais de 8 meses!"

Senhor Fabrício: "Eu sabia o que o médico estava dizendo. Conheço algumas pessoas que passaram pela mesma situação. Os médicos acham que estão ajudando mas, no caso do meu pai, eu sabia, eu sentia que a coisa era grave, era doença ruim, era ... câncer. Eu sabia que não podia suavizar a situação. Algo me dizia que era grave, a minha experiência com amigos e conhecidos".

Assim, os conhecimentos dos familiares, as suas percepções e crenças sobrepõem às informações do médico e ao seu poder social.

Neste momento, o significado pessoal e social da "doença", enquanto algo ruim, fatal, de muito sofrimento, enaltece o estigma social e cultural do câncer por meio de metáforas: "Foi um trovão na nossa cabeça", "Foi uma trombada", "Parecia que uma tempestade caia sobre a gente".

Joana (filha do Sr José): "Não, não tinha passado na minha cabeça que era "a doença", de jeito nenhum! Quando o médico me disse da endoscopia e da biópsia... Deus, foi um choque! Eu sei para que eles são!"

Senhor Roberto: "Eu sempre evitei ler sobre isso. Eu nunca pensei que fosse acontecer comigo! Eu tinha saúde, era normal, fumando e bebendo, era feliz! A gente sempre acha que isso não acontece com a gente! Eu nunca tinha ido ao médico! Eu não gosto de médico e nem de hospital! É aí que a gente se engana. A vida dá uns trotes na gente! A cada dia ela dá uma surpresa! Isso não podia acontecer comigo... mas, aconteceu! Quando mais você vive, mais aprende, e morre sem saber. Depois fui ao médico... Ele não falava o que eu tinha... me enrolava... com o tempo fui percebendo o que eu tinha, a minha família também, foi um sofrimento, o meu filho falou um dia: Pai, não tem jeito, só pode ser doença ruim... Deus, foi triste, mas era isso mesmo, doença ruim...!"

\subsection{O SIGNIFICADO DE SUBMETER-SE AO TRATAMENTO MEDICO}

Frente ao significado da doença, as perspectivas do paciente e da familia tornam-se ameaçadas, assim, a alternativa para todos é depositar confiança na decisão médica pelo futuro. Por sua vez, o cirurgião possuído do poder decisório, fornece a única decisão terapêutica ao seu alcance (dentro do seu contexto de referência): realizar a cirurgia no paciente. Ao paciente e família restam apenas duas opções: aceitar o tratamento proposto e ter uma esperança de vida ou sucumbir à doença. De qualquer modo, para o paciente e família, essa decisão é um processo dialético entre a expectativa de cura e a perspectiva da morte. Entretanto, como mecanismo de sobrevivência, o paciente sob forte influencia da rede familiar, busca pela expectativa social de "sobreviver à cirurgia".

Nesta significação, o tratamento cirúrgico têm maior importância, apesar da sua mutilação, do que as outras associações terapêuticas. A radioterapia póscirúrgica é considerada de menor importância em relação à cirurgia, "é esperado fazer esse tratamento depois da cirurgia, nessa doença", "... isso é normal para a doença que eu tinha".

Senhor Francisco: "A garganta estava fechando cada vez mais, a respiração estava dificil, estava dificil eu comer. O médico contou que era um tumorzinho! Eu sei... eu sei o que era... Ai eu pensei, não tem jeito, o que o médico falar está falado! Ele estudou para isso! Se eu não acreditar nele, em quem vou acreditar? Ele é médico! Ai, o médico disse que tinha de operar senão a garganta ia fechar e eu ia morrer. Eu pensei: morrer ou fazer a cirurgia $e$ esperar por não morrer! Para mim, é importante viver! Eu tinha um tumor, não tem jeito, tinha que operar mesmo sabendo como ia ficar! Era morrer ou operar!"

\subsection{OS RITUAIS DE INFORTÚNIOS}

$\mathrm{Na}$ busca por compreender o adoecimento, a doença e o tratamento, há a integração da rede de apoio familiar e social (amigos e vizinhos) que buscam soluções no seu contexto de conhecimentos e crenças.

A condição de doença sempre está ligada ao significado de sofrimento por causa do modo como a relação entre o corpo e o self é mediado por símbolos 
culturais da religião, da moral ou do espírito (KLEINMAN, 1988). A realidade social é construída a partir de certos significados e comportamentos que são culturalmente legitimados, "eu acho que o que está acontecendo, ele (o paciente) está sofrendo, nós estamos sofrendo, sofrer faz parte da doença".

$\mathrm{Na}$ busca por soluções para o sofrimento, os rituais de infortúnios surgem como alternativas para conviver com a situação. Estes rituais são fundamentados no paradigma moral e religioso de controle social, que transforma a angústia em um comportamento sancionado pelo grupo social para transcender a dor e a perspectiva de morte pela doença crônica (KLEINMAN, 1988; GARRO, 1994; HELMAN, 1994). São exemplos de rituais de infortúnios: o choro coletivo, as rezas, as promessas religiosas e as novenas envolvendo paciente, familia e amigos ou vizinhos.

A relação da doença crônica com o sofrimento evoca duas questões para o paciente e o seu grupo social: porque eu? (questão de perplexidade), o que fazer? (questão de ordem e controle). Para KLEINMAN (1988), todas as perspectivas de cura nas diferentes culturas, como as perspectivas religiosas e morais, orientam as pessoas doentes e o seu circulo social para o problema da perplexidade, porém, o modelo biomédico foge deste aspecto de sofrimento. Assim, a família, com seus valores morais e religiosos, transformam o sofrimento em uma experiência de lidar com os processos culturais para transcender a dor e a perspectiva de morte.

Manieta (filha do sr. Francisco): "Ele estava sofrendo, eu estava sofrendo. Minha mãe chorava o dia todo. Meu irmão que mora em outra cidade telefonava e chorava, todo mundo chorava, lamentava e rezava. Os amigos, parentes e vizinhos fizeram uma novena. Foi muito bom! Ajudou! Ajudou a aceitar o problema, a aceitar o que aconteceu, o que ele passou, como ele ficou. Deus sempre ajuda quem reza!"

\subsection{AS CAUSAS DA DOENÇA}

Neste momento, na perspectiva cultural, o paciente e familiares buscam por explicações lógicas das causas do câncer. Nas narrativas dos laringectomizados e seus familiares, as etiologias ou responsabilidades pela doença emergem da atribuição a uma combinação de causas ou a interação entre diferentes mundos:

- No mundo pessoal: a responsabilidade pela doença recai sobre o próprio indivíduo, mas, ele não tem controle consciente. Esta atribuição está relacionada a vulnerabilidade fisica: resistência ou fraqueza pela idade, predisposição hereditária (na transmissão genética de uma doença, qualidade ou traço peculiar), degeneração da estrutura e funcionamento do corpo pelo envelhecimento:
- Senhor João: "Otha, eu acho que eu tive a doença porque eu estou ficando velho. Também, pode ser porque eu tenho um tio que morreu da mesma doença, na laringe. Acho, eu acho que ele passou a doença para o meu sangue, sabe... Ele deixou isso para mim!"

- No mundo social: devido aos conflitos interpessoais e a natureza moral e afetiva com familiares:

- Joana (filha do senhor Roberto): "Com a aposentadoria, ele começou a brigar muito com a minha mãe. Isso levou a depressão e a braveza... e veio a doença!". "Ele não pode cuidar do pai que tinha câncer. Mas eles se davam muito bem. Assim, ele acabou plasmando a doença do pai."

- No mundo sobrenatural: a doença é um alerta de Deus para um determinado lapso de comportamento:

- Senhor Roberto: "Foi o destino. Deus me puniu pelos meus pecados. Acho que foi Deus! Deus sabe o que faz com a gente. O que a gente faz, a gente paga... um dia. A doença foi coisa de Deus! Eu fiquei assim para redimir das minhas culpas! Se Deus quiser, eu vou sair dessa!"

Os significados marcam as pessoas com câncer, impondo uma estampa não esperada e não desejada, com a qual ela tem dificuldade de lidar. A marca ou estampa pode ser o estigma ou a morte social. Embora o significado da doença possa ser ambíguo, as suas conseqüências podem ser modificadas pelo ambiente do paciente, no seu contexto cultural. As pessoas alteram os seus recursos para resistir ou re-trabalhar os significados da doença, buscando o sentido de normalidade.

Segundo KLEINMAN (1994) e LOCK; SCHEPER-HUGHES (1990) a pessoa doente é o corpo doente (self) e reconhece que tem um corpo doente que é uma identidade diferente. Consequentemente, a pessoa transcende seu corpo e distancia-se, de modo alienado, da doença. O recurso utilizado por ela é buscar responsabilidades para a doença, nos diferentes mundos da sua cultura. Desse modo, a cultura preenche o espaço entre a incorporação da doença, como processo biológico, e a experiência de viver a doença, como fenômeno humano, separando o corpo e o self. A doença toma o sentido de sofrimento porque a relação entre corpo e self é mediada pelos símbolos culturais da religião, da moral, do espírito.

O adoecimento pelo câncer de laringe pode gerar respostas comuns como medo, tristeza, sofrimento ou raiva. Entretanto, essas reações podem diferir devido ao contexto cultural das pessoas. A cultura latina inclue uma ampla e diversa variedade de tradições, crenças, atitudes e mitos que têm um impacto sobre o modo como os latinos vivem a experiência de ter câncer (GRANDA-CAMERON, 1998). 
Senhor Romualdo: "Olha, eu nunca acreditei que o fumo faz mal. Veja, tem tanta gente que fuma a vida inteira e nada acontece. Eu também bebia, mas não acho que ela faz mal. No fundo, no fundo, acho que é porque eu estou velho, o meu corpo está fraco e não reage! Também, o meu tio morreu da doença. Eu tenho outros parentes que morreram da doença. Também, eu não fui uma pessoa... uma pessoa que fez o bem... Acho que tudo isso importa, um pouco de cada coisa... Foi Deus que quis assim, é um desafio, uma provação, estou pagando pelos meus erros..."

Ronaldo (filho do senhor Paulo): "Sabe, eu acho que o mais importante é que a doença foi tirada, graças a Deus! Isso é o que importa! Agora, ele está bem. Não fala mas está bem! A doença acabou e ele está vivo! A cirurgia fez isso! Todo o sofrimento, tudo o que nós passamos, valeu! Valeu porque ele está vivo. Isso importa muito. $O$ resto, o resto, a gente dá um jeito, a gente entende o que ele quer falar, quer fazer, a gente ajuda no que pode. Não sei se ele está feliz. Mas o que importa é que ele passou a cirurgia e está vivo!"

\section{CONSIDERAÇÕES FINAIS}

O paciente e familia, na busca por compreender a situação em que estão vivendo, integram uma estrutura de referência sociocultural lógica, que nem sempre é considerada pelos agentes de saúde que participam do seu processo de assistência e que muitas vezes negligenciam esses significados, tornando suas ações verbais e não verbais incoerentes e inconsistentes.

Pelas narrativas do adoecimento pelo câncer de laringe entre os participantes do estudo, alguns pressupostos se destacam:

- a doença estigmatizada, o câncer, foi causada principalmente por fatores externos sob os quais nem o paciente e nem a família têm controle;

- o tratamento cirúrgico e as medidas terapêuticas associadas, integrados ao significado da "doença", ao poder médico, ao apoio familiar e dos amigos, e a religiosidade, favoreceram o sobreviver a cirurgia;

- a realidade clínica da atual condição de saúde dos pacientes, envolve a dialética da normalidade e anormalidade (segundo o referencial sociocultural do paciente/familia), quando a normalidade refere-se a sobrevivência ao câncer $\mathrm{e}$ na manutenção das atividades diárias mínimas (como comer, andar, ajudar nas atividades domésticas). A anormalidade refere-se as conseqüências mutilatórias da cirurgia pela alteração da comunicação (afonia), da imagem corporal (traqueostomia permanente) e pela aposentadoria não planejada, que determinam a lamentação pelas perdas nos relacionamentos interpessoais e sociais (dependência na familia $\mathrm{e}$ isolamento social).

O Modelo Explicativo descrito forma um todo integrado, lógico e significativo. O significado do adoecimento e do tratamento são uma ponte simbólica que conecta o corpo, o self, a cultura e a sociedade. Essa estrutura conecta processos fisiológicos, significados e relações, de modo que o mundo sociocultural do indivíduo e da sua família sejam unidos continuamente à experiência internado indivíduo.

Consideramos que esse modelo está situado em um ponto intermediário do continuum entre o modelo leigo e o modelo médico. Eles mostram semelhanças e contradicōes com o modelo médico vigente (visto que o modelo médico não considera a influência cultural). Essas contradições podem levar a intervenções terapêuticas ineficazes e a baixa adesão dos pacientes aos tratamentos.

Enquanto profissionais que atuam na reabilitação desses pacientes, com a participação de seus familiares, compreender o adoecimento dos laringectomizados e de seus familiares, sob o enfoque cultural, é um ponto chave para desenvolver o apoio e a educação para a reabilitação.

\section{REFERÊNCIAS BIBLIOGRÁFICAS}

ALVES, PC. A experiência da enfermidade:considerações teóricas. Cad Saúde Pública, v.9, n.3, p.263-71, 1993.

COFFEY, A; ATKINSON, P. Making sense of qualitative data: complementary research strategies. Thousands Oaks: Sage. 1996.

FLICK, UWE. An introduction to qualitative research. London: Sage.1998.

GARRO, LC. Chronic Illness And The Construction Of Narratives. In: GOOD, MD. et al. Pain as human experience: an anthropological perspective. Berkeley, University California Press. 1994. Cap. 5, p.100-37.

GRANDA-CAMERON, C. The experience of having cancer in Latin America. Cancer Nurs, v.22, n.1, p,51-7, 1999.

HELMAN, CG. Cultura, saúde e doença. 2.ed. Porto Alegre: Artes Médicas, 1994.

KLEINMAN, A. The illness narratives: suffering, healing, and the human condition. United States of America: Basic Books, 1988

LOCK, M.; SCHEPER-HUGHES, N. A critical-interpretative approach in medical anthropology: rituals and routines of discipline and dissent. In: JOHNSON, TM.; SARGENT, CF. Medical anthropology: contemporary theory and method New York: Praeger, 1990. Cap.3, p.47-72.

NAVON, L. Voices from the world: cultural views of cancer around the word. Cancer Nurs, v.22, n.1, p.39-45, 1999.

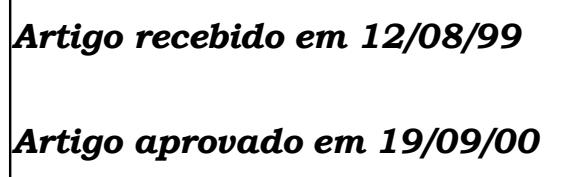

